\title{
The Effect of Valley Location in Two-Process Surface Topography Analysis
}

\author{
Przemysław Podulka ${ }^{1}$ \\ 1 Rzeszow University of Technology, al. Powstańców Warszawy 12, 35-959 Rzeszów, Poland \\ e-mail: p.podulka@prz.edu.pl
}

\begin{abstract}
In this paper the influence of oil pockets location on extraction of surface topography features was taken into account. Plateau-honed cylinder liners with additionally added dimples were taken in consideration. The effect of dimples location on the application of various procedures (cylinder fitting procedure, polynomial approximation) for areal form removal was taken into account. It was noticed that application of 3rd (or greater) degree of the polynomials can caused false estimation of reference plane; extraction of surface topography features by polynomial approximation cannot provide good results when the distance between dimples is too small. For two-process surfaces (plateau-honed cylindrical elements containing wide and deep valleys) the digital filtering was proposed. Application of robust techniques (robust Gaussian regression filter) allowed for areal form removal improvement. However, some of the wide dimples were distorted when the dimple-to-edge distance was too small (smaller than filter bandwidth value).
\end{abstract}

Keywords: surface topography, dimples, cylinder liners, measurement, measurement errors

\section{INTRODUCTION}

The study of surface topography can give quantitative information about friction surfaces. Usually the surface topography parameters are calculated after form removal: error of shape and/ or waviness (as an imperfection of manufacturing process) [1]. Plenty of articles and research items deals with extraction of surface topography features (STF) by application of various digital processing techniques [2]. There are many algorithms and/or procedures dedicated for surface topography measurements and/or analysis [3-5]. However, only few of treats about measurement errors [6-8], dimple distortions [9] or problems in surface topography parameter calculations [10]. It was recommended to propose the procedure of STF according to the type of measured detail [11].

For surface topography measurement inaccuracy - including the properties of measured surface, measuring equipment and techniques - the digital filtering and interpretation of the received results are also crucial [12]. Improper selection of procedure for extraction of functional features of surfaces is of great importance. Plateau-honed cylinder liner surface is a much-quoted example of this type of surfaces [13]; falsely estimation of algorithm can cause the classification of properly made parts as a lack and its rejection.

STF were performed by many procedures [14-21]; measurement and/or analysis of twoprocess surface is particularly significant when dimples are edge-located [22-24]. In this paper the influence of valley distribution on extraction of STF of cylinder liners from car engines was studied and performed.

\section{MATERIALS AND METHODS}

Plateau-honed cylinder liners with additionally added oil pockets from car engines were studied. The depth of dimples was between $20 \mu \mathrm{m}$ and $130 \mu \mathrm{m}$; width between $0.4 \mathrm{~mm}$ and $1.2 \mathrm{~mm}$. Examples of studied surfaces: measured (a), surfaces with modelled dimples (b) and material ratio curves $(c, d)$, selected parameters $(e, f)$ were presented in Figure 1. 
The effect of extraction of STF on parameter calculations (from ISO 25178 standard) was taken into account. The measuring equipment was: white light interferometer Talysurf CCI Lite (height resolution $0.1 \mathrm{~nm}$ ) and/or Talyscan 150 stylus equipment (nominal tip radius about $2 \mu \mathrm{m}$, height resolution about $10 \mathrm{~nm}$ ). More than 40 measured and 40 with modelled (digitally added) dimples surfaces were taken into consideration. The maximum size of surface was $5 \mathrm{~mm}$ by $5 \mathrm{~mm}$ (some of the elements were studied in detail and/or profile extractions), the spacing was from $3.27 \mu \mathrm{m}$ (optical measurement) to $5 \mu \mathrm{m}$ (stylus method).

Extraction of STF was proposed by: leastsquare fitted cylindrical element $\left(\mathrm{C}^{\mathrm{LSM}}\right)$, polynomials from $2^{\mathrm{ND}}\left(\mathrm{P}^{2 \mathrm{ND}}\right)$ to $4^{\mathrm{TH}}\left(\mathrm{P}^{4 \mathrm{TH}}\right)$ degrees and digital schemes (robust Gaussian regression filter $-\mathrm{F}^{\mathrm{RGR}}$ ). The effect of application of procedures was studied with particular attention to: dimpleto-dimple distance $\left(\mathrm{D}_{\mathrm{DD}}\right)$, dimple-to-edge distance $\left(\mathrm{D}_{\mathrm{DE}}\right)$, width (size) of the dimple $\left(\mathrm{D}_{\mathrm{W}}\right)$; the

a)

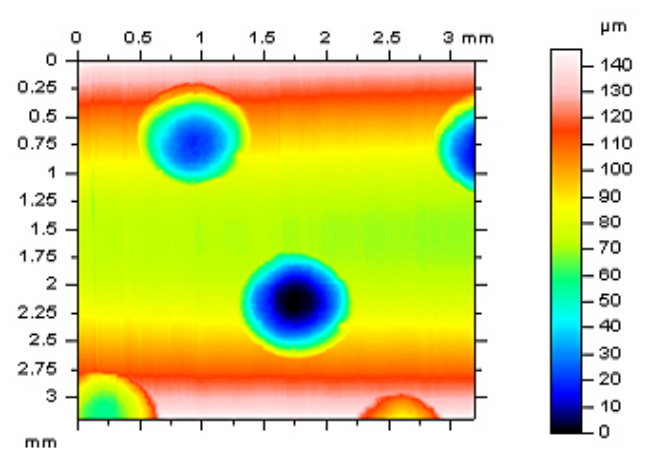

c)

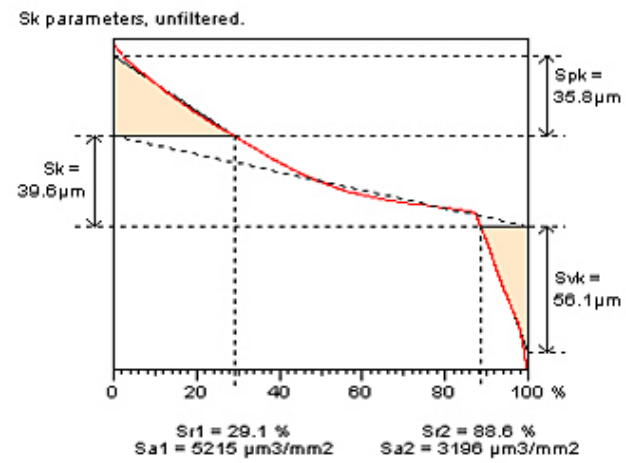

e) $\mathrm{Sg}=28.1 \mu \mathrm{m}$;

$$
\begin{aligned}
& \mathrm{Ssk}=-0.297 ; \\
& \mathrm{Sku}=3.29 ; \\
& \mathrm{Sp}=59.1 \mu \mathrm{m} ; \\
& \mathrm{Sv}=87.2 \mu \mathrm{m} ; \\
& \mathrm{Sz}=146.3 \mu \mathrm{m} ; \\
& \mathrm{Sa}=22.0 \mu \mathrm{m} .
\end{aligned}
$$

distortions of dimple-to-dimple $\left(\mathrm{A}_{\mathrm{DD}}\right)$ and dimple-to-edge $\left(\mathrm{A}_{\mathrm{DE}}\right)$ areas were also taken into account. The filter bandwidth (cut-off) value $\left(\mathrm{F}_{\mathrm{BDW}}\right)$ was also defined.

The effect of dimple location was studied for the following parameters: root mean square height Sq, skewness Ssk, kurtosis Sku, maximum surface peak height $\mathrm{Sp}$, maximum valley depth $\mathrm{Sv}$, maximum height $\mathrm{Sz}$, arithmetic mean height $\mathrm{Sa}$; Sk group parameters: reduced summit height Spk, reduced valley depth Svk, core roughness depth Sk, upper bearing area $\mathrm{Sr} 1$ and lower bearing area $\mathrm{Sr} 2$.

\section{RESULTS AND DISCUSSIONS}

Application of $\mathrm{C}^{\mathrm{LSM}}$ fitting did not allow to remove form correctly (a) - the isometric view analysis from figure 2 - the reference plane was also incorrectly defined when $\mathrm{P}^{2 \mathrm{ND}}$ (c) or $\mathrm{P}^{4 \mathrm{TH}}$ (e) were applied; the form was incompletely re-

b)

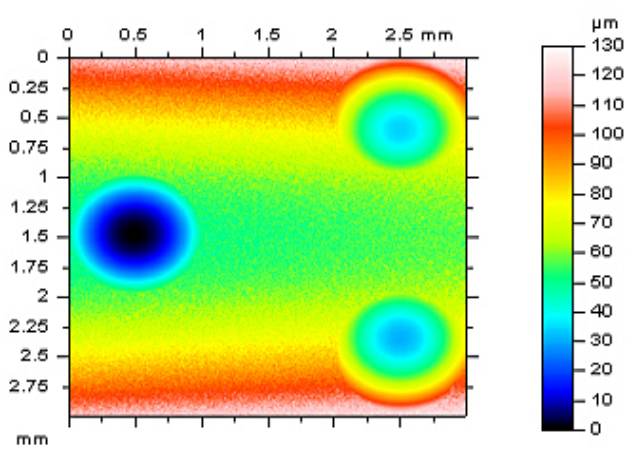

d)

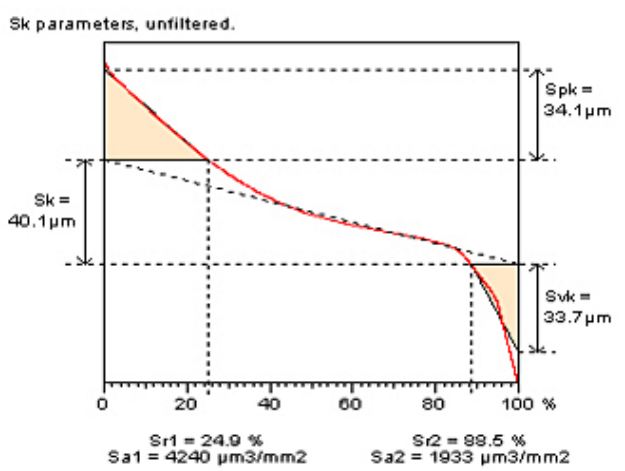

f) $\mathrm{Sq}=24.3 \mu \mathrm{m}$;

$$
\begin{aligned}
& \mathrm{Ssk}=0.065 ; \\
& \mathrm{Sku}=3.03 \\
& \mathrm{Sp}=61.0 \mu \mathrm{m} \\
& \mathrm{Sv}=69.0 \mu \mathrm{m} \\
& \mathrm{Sz}=130.0 \mu \mathrm{m} ; \\
& \mathrm{Sa}=19.2 \mu \mathrm{m} .
\end{aligned}
$$

Fig. 1. Cylinder liner surface contour plots of: measured (a), with modelled dimples (b), their material ratio curves $(c, d)$ and selected parameters $(e, f)$ respectively 
moved. Falsely estimated reference plane can be also noticed with profile exploration (figure 2). The increase of polynomial degree can cause the increment of the dimples distortion.

When $\mathrm{D}_{\mathrm{DD}}<1 \mathrm{~mm}$ and/or $\mathrm{D}_{\mathrm{DE}}<0.5 \mathrm{~mm}$ then application of polynomials (even the $2^{\mathrm{ND}}$ degree) can caused the reference plane as well as oil pockets distortion.

STF distinguishing of functional surface was often proposed by application of robust Gaussian regression filter. This type of digital filtering is characterized that they are robust for all the freaky values and/or outliers (such as spikes or dimples). When $\mathrm{D}_{\mathrm{DE}}<\mathrm{F}_{\mathrm{BDW}}$ then distortion of dimples (as well as $\mathrm{A}_{\mathrm{DD}}$ in analysed detail) increased; position of reference plane was defined incorrectly. In some cases the $\mathrm{A}_{\mathrm{DE}}$ have a tendency to distort despite of oil pockets not; when dimples were located near/on the edge of measured surface, the distortion was the biggest (figure 3-a). Some changes were also noticeable on the near-dimple areas (and located relatively away from the edge $-\mathrm{D}_{\mathrm{DE}}>1 \mathrm{~mm}$ ) of the studied surface (it was indicated by the arrows in figure $4 \mathrm{a}-\mathrm{c}$ ). Distortion of dimples has a negative impact on the values of surface topography parameters: Sp was overestimated around 20\%; Sz increased around 30\%; Spk increased twice; Svk decreased more than 50\%; parameters were shown in Figure 3.

When $\mathrm{D}_{\mathrm{DD}}<\mathrm{D}_{\mathrm{w}}$ then distortion of area between dimples increased even $\mathrm{F}_{\mathrm{BDW}}>\mathrm{D}_{\mathrm{W}}$ (figure 5-b). However when $\mathrm{D}_{\mathrm{w}}<\mathrm{D}_{\mathrm{DD}}$ and $\mathrm{D}_{\mathrm{W}}<\mathrm{F}_{\mathrm{BDW}}$ then distortion of dimples and the near-dimple areas (as well as $\mathrm{A}_{\mathrm{DD}}$ and/or $\mathrm{A}_{\mathrm{DE}}$ ) did not exist (or appeared to be insignificant) - Figure 5-a. a)

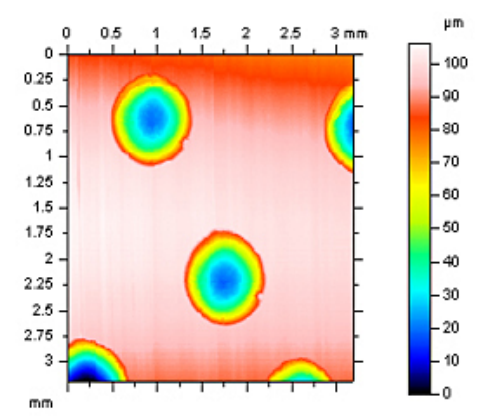

b)

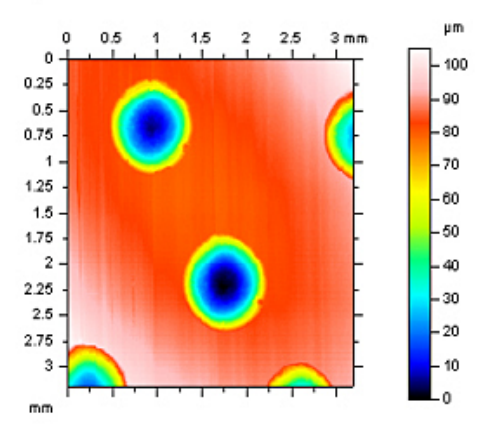

c)

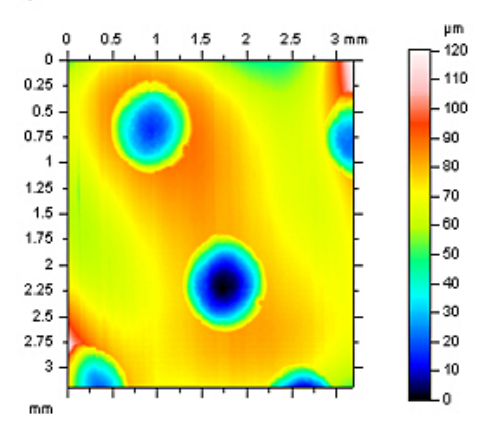

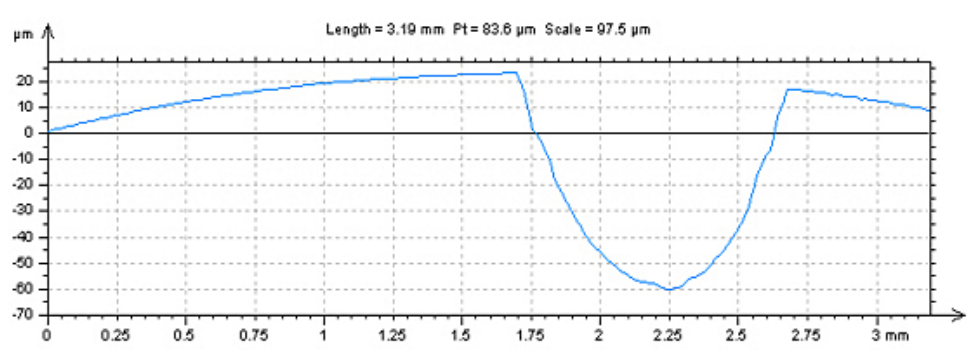

$\mathrm{Sq}=20.3 \mu \mathrm{m}, \mathrm{Ssk}=-2.48, \mathrm{Sku}=7.6, \mathrm{Sp}=14.1 \mu \mathrm{m}$,

$\mathrm{Sv}=91.9 \mu \mathrm{m}, \mathrm{Sz}=106 \mu \mathrm{m}, \mathrm{Sa}=12.5 \mu \mathrm{m}$

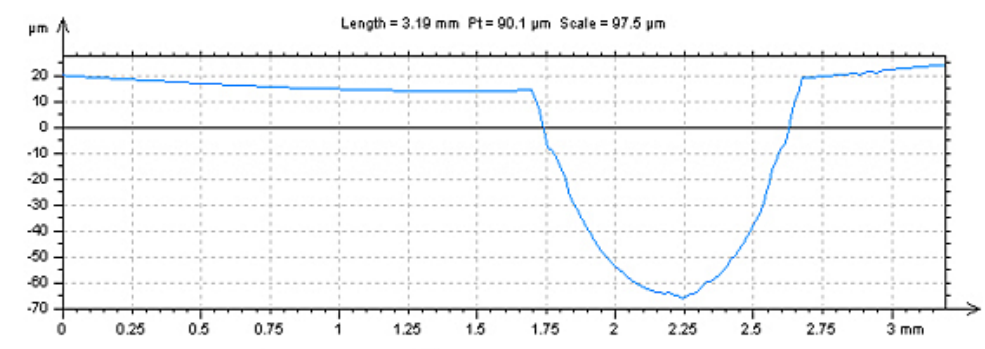

$\mathrm{Sq}=20.6 \mu \mathrm{m}, \mathrm{Ssk}=-2.74, \mathrm{Sku}=8.58, \mathrm{Sp}=20.9 \mu \mathrm{m}$,

$\mathrm{Sv}=84.4 \mu \mathrm{m}, \mathrm{Sz}=105.3 \mu \mathrm{m}, \mathrm{Sa}=10.6 \mu \mathrm{m}$

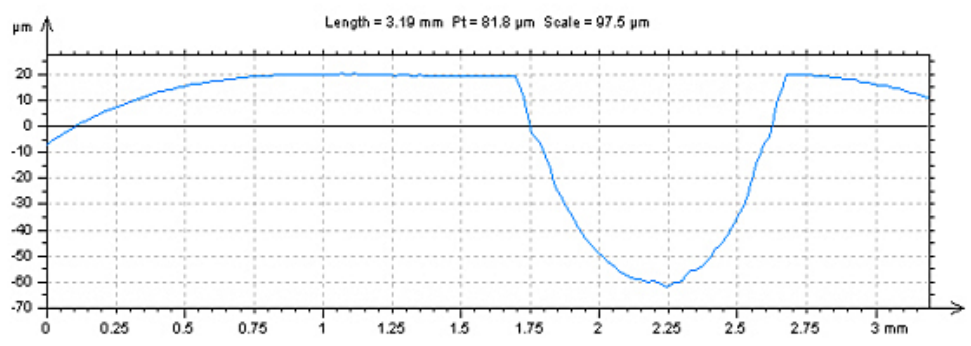

$\mathrm{Sq}=16.3 \mu \mathrm{m}, \mathrm{Ssk}=-1.68, \mathrm{Sku}=6.17, \mathrm{Sp}=52.7 \mu \mathrm{m}$,

$\mathrm{Sv}=67.7 \mu \mathrm{m}, \mathrm{Sz}=120.4 \mu \mathrm{m}, \mathrm{Sa}=11.2 \mu \mathrm{m}$

Fig. 2. Cylinder surface plots after STF distinguishing by: CLSM (a), P2ND (b) and P4TH (c); and selected profiles with parameters respectively. 
a)

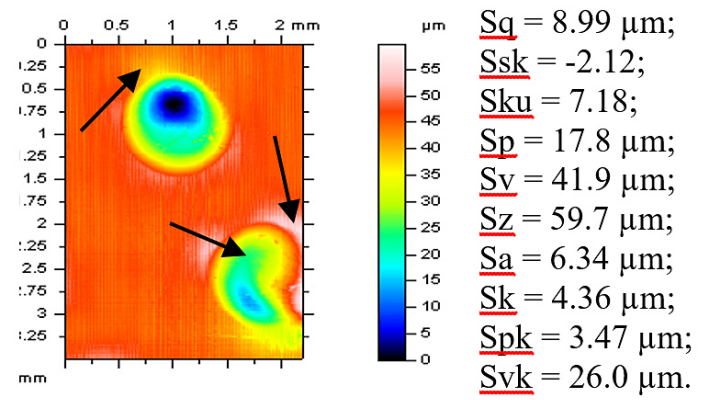

b)

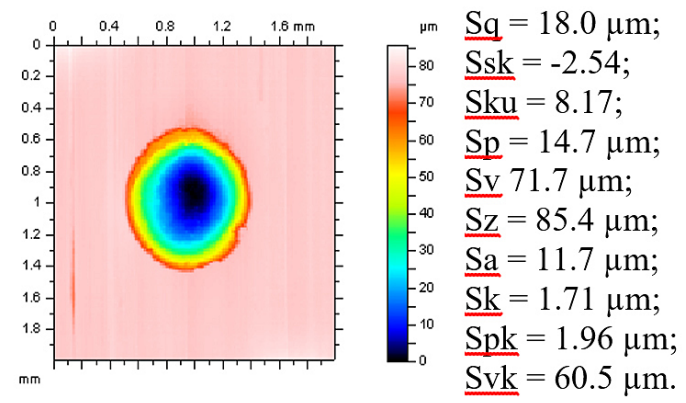

Fig. 3. Surface contour plots of cylinder liner after STF distinguishing by FRGR (FBDW $=0.8 \mathrm{~mm}$ ) containing dimples with different distribution: near-edge located oil pockets (a) or located in the middle of analysed detail (b)

a)

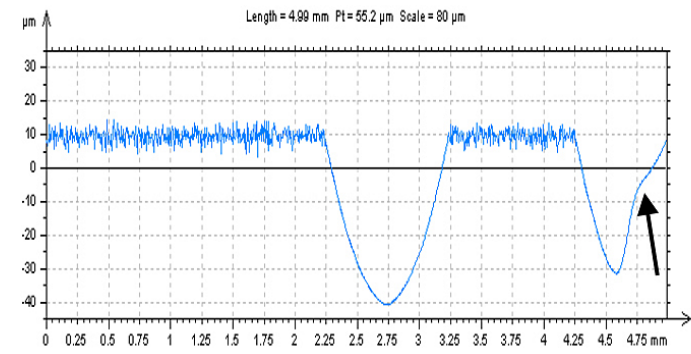

c)

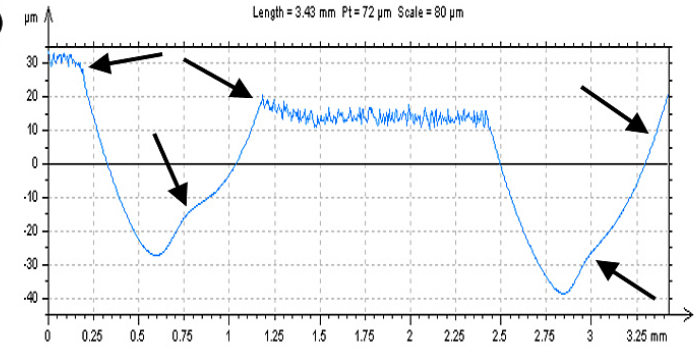

b)

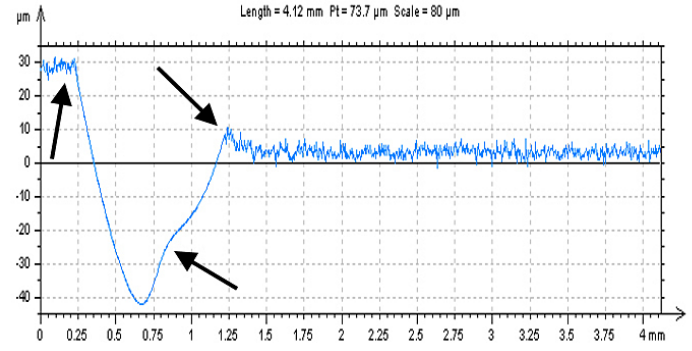

d)

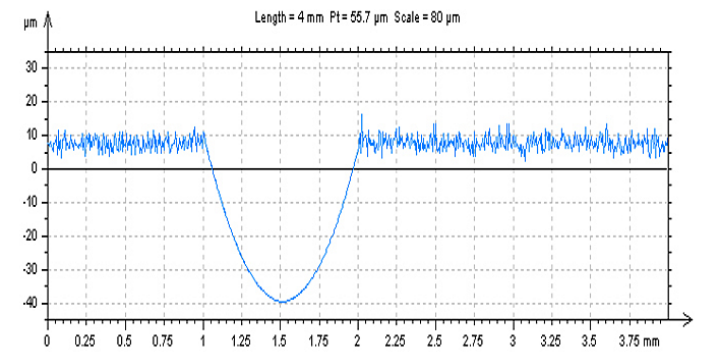

Fig. 4. Extracted profiles of surface after application of FRGR, FBDW $=0.8 \mathrm{~mm}$

a)

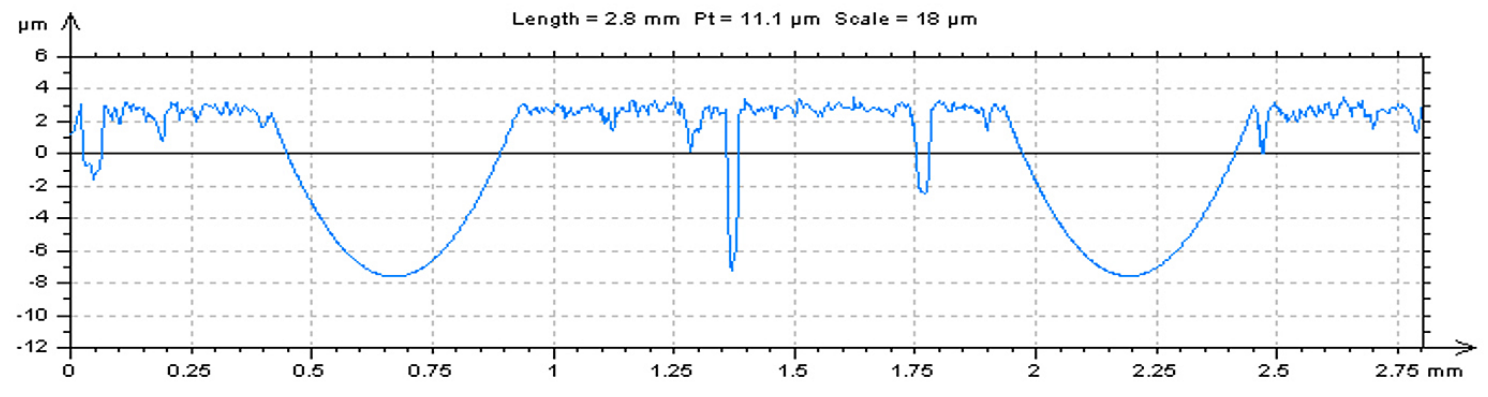

b)

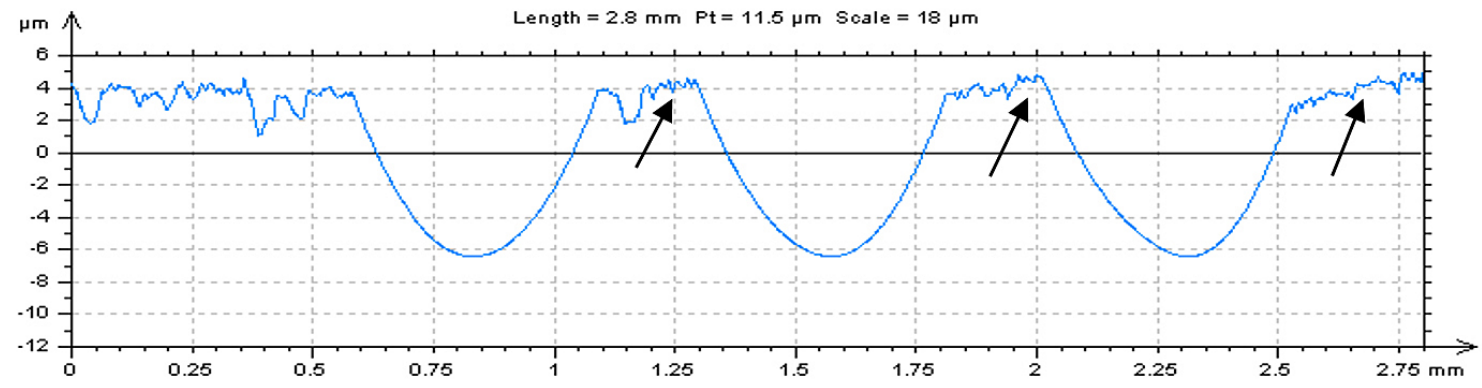

Fig. 5.. Extracted profiles from surface after digital filtering; DDD $=1 \mathrm{~mm}$ (a) and DDD $=0.2 \mathrm{~mm}($ b) approximately 
After the analysis of the extracted details (figure 6) from surface (after shape/waviness elimination) the following conclusions were noticed. Application of $\mathrm{P}^{2 \mathrm{ND}}, \mathrm{P}^{3 \mathrm{RD}}$ or $\mathrm{P}^{4 \mathrm{TH}}$ caused false estimation of reference plane when $\mathrm{D}_{\mathrm{DD}}<1 \mathrm{~mm}$; usually distortion increased when the dependence $\mathrm{D}_{\mathrm{DE}}<0.5 \mathrm{~mm}$ was also accomplished.

Application of $F^{R G R}$ caused the minimization of surface topography height parameters, which were taken into account. The value of $\mathrm{Sq}$ was twice smaller after application of digital filtering compared with polynomials (from $2^{\mathrm{ND}}$ to $4^{\mathrm{TH}}$ degrees); the values of $\mathrm{Sp}, \mathrm{Sz}$ and Spk parameters decreased more than $100 \%$ (in some cases).

When $\mathrm{D}_{\mathrm{W}}>0.5 \mathrm{~mm}$ then the application of digital filtering $\left(\mathrm{F}^{\mathrm{RGR}}\right)$ is necessary instead of $\mathrm{C}^{\mathrm{LSM}}$ or polynomial approximation ( $2^{\mathrm{ND}}$ or higher degree).

\section{CONCLUSIONS}

Application of $\mathrm{C}^{\mathrm{LSM}}$ did not allow to extract STF correctly when $\mathrm{D}_{\mathrm{w}}>0.5 \mathrm{~mm}$; it is recommended to select the reference plane by polynomial or digital filters appliance.

The STF were properly selected after application of $\mathrm{P}^{2 \mathrm{ND}}$ when $\mathrm{D}_{\mathrm{w}}<0.5 \mathrm{~mm}, \mathrm{D}_{\mathrm{DD}}>1 \mathrm{~mm}$ and $\mathrm{D}_{\mathrm{DE}}>0.5 \mathrm{~mm}$; otherwise the distortions of oil pockets and $A_{D D}$ and $A_{D E}$ of the studied detail increased - digital filtering is suggested.

Application of $\mathrm{F}^{\mathrm{RGR}}$ caused the distortion of dimples (as well as $\mathrm{A}_{\mathrm{DD}}$ and $\mathrm{A}_{\mathrm{DE}}$ ) when $\mathrm{D}_{\mathrm{DE}}<\mathrm{F}_{\mathrm{BDW}}$. Irregularities in STF extraction were also noticeable on the near-dimple areas, located further than $1 \mathrm{~mm}$ from the edge of analysed surface $\left(D_{D E}>1 \mathrm{~mm}\right)$. a)

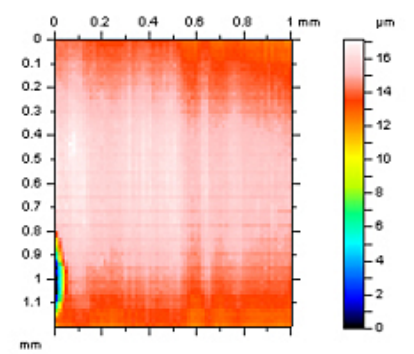

c)

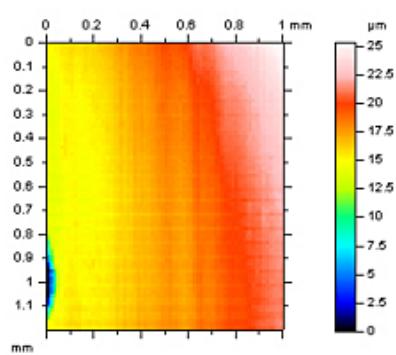

e)

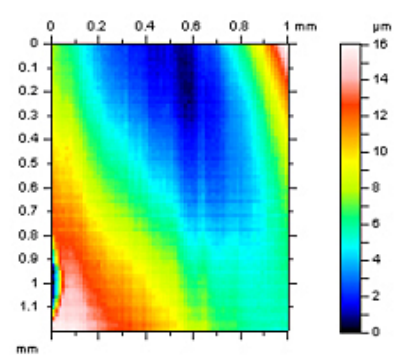

g)

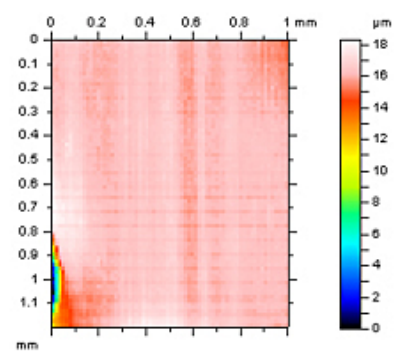

$\mathrm{Sq}=1.29 \mu \mathrm{m}$

$\mathrm{Sp}=2.29 \mu \mathrm{m}$;

$\mathrm{Sv}=14.8 \mu \mathrm{m}$;

$\mathrm{Sz}=17.1 \mu \mathrm{m}$

$\mathrm{Sa}=0.895 \mu \mathrm{m}$;

$\mathrm{Sk}=2.36 \mu \mathrm{m}$;

$\mathrm{Spk}=0.331 \mu \mathrm{m}$;

$\mathrm{Svk}=1.73 \mu \mathrm{m}$.

$\mathrm{Sq}=3.78 \mu \mathrm{m}$;

$\mathrm{Sp}=7.37 \mu \mathrm{m}$;

$\mathrm{Sv}=17.9 \mu \mathrm{m}$;

$\mathrm{Sz}=25.3 \mu \mathrm{m}$;

$\mathrm{Sa}=2.21 \mu \mathrm{m}$;

$\mathrm{Sk}=6.70 \mu \mathrm{m}$;

$\mathrm{Spk}=2.47 \mu \mathrm{m}$;

$\mathrm{Svk}=4.91 \mu \mathrm{m}$.

$\mathrm{Sq}=3.37 \mu \mathrm{m}$;

$\mathrm{Sp}=9.75 \mu \mathrm{m}$;

$\mathrm{Sv}=6.29 \mu \mathrm{m}$;

$\mathrm{Sz}=16.0 \mu \mathrm{m}$;

$\mathrm{Sa}=2.73 \mu \mathrm{m}$;

$\mathrm{Sk}=8.02 \mu \mathrm{m}$;

$\mathrm{Spk}=4.27 \mu \mathrm{m}$;

$\mathrm{Svk}=0.889 \mu \mathrm{m}$.

$\mathrm{Sq}=1.03 \mu \mathrm{m}$;

$\mathrm{Sp}=2.02 \mu \mathrm{m}$;

$\mathrm{Sv}=16.3 \mu \mathrm{m}$;

$\mathrm{Sz}=18.3 \mu \mathrm{m}$;

$\mathrm{Sa}=0.39 \mu \mathrm{m}$;

$\mathrm{Sk}=0.823 \mu \mathrm{m}$;

$\mathrm{Spk}=0.77 \mu \mathrm{m}$;

$\mathrm{Svk}=2.34 \mu \mathrm{m}$. b)

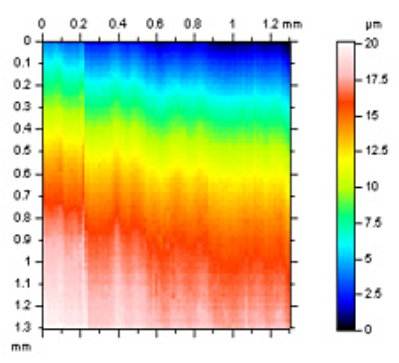

d)

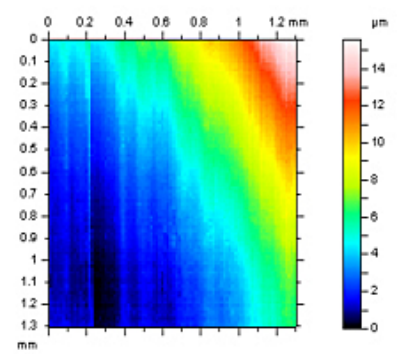

f)

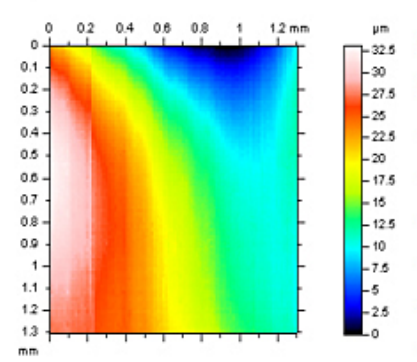

h)

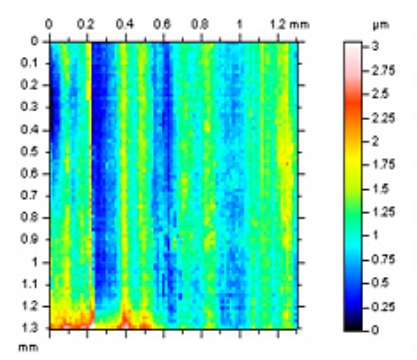

$\mathrm{Sq}=5.01 \mu \mathrm{m}$;

$\mathrm{Sp}=8.05 \mu \mathrm{m}$;

$\mathrm{Sv}=12.2 \mu \mathrm{m}$;

$\mathrm{Sz}=20.2 \mu \mathrm{m}$;

$\mathrm{Sa}=4.29 \mu \mathrm{m}$;

$\mathrm{Sk}=10.6 \mu \mathrm{m}$;

$\mathrm{Spk}=1.02 \mu \mathrm{m}$;

$\mathrm{Svk}=6.52 \mu \mathrm{m}$.

$\mathrm{Sq}=3.23 \mu \mathrm{m}$;

$\mathrm{Sp}=10.9 \mu \mathrm{m}$;

$\mathrm{Sv}=4.65 \mu \mathrm{m}$;

$\mathrm{Sz}=15.6 \mu \mathrm{m}$;

$\mathrm{Sa}=2.61 \mu \mathrm{m}$;

$\mathrm{Sk}=6.54 \mu \mathrm{m}$;

$\mathrm{Spk}=5.24 \mu \mathrm{m}$;

$\mathrm{Svk}=0.537 \mu \mathrm{m}$.

$\mathrm{Sq}=7.87 \mu \mathrm{m}$;

$\mathrm{Sp}=15.7 \mu \mathrm{m}$;

$\mathrm{Sv}=17.3 \mu \mathrm{m}$;

$\mathrm{Sz}=33.0 \mu \mathrm{m}$;

$\mathrm{Sa}=6.85 \mu \mathrm{m}$;

$\mathrm{Sk}=19.8 \mu \mathrm{m}$;

$\mathrm{Spk}=5.51 \mu \mathrm{m}$;

$\mathrm{Svk}=4.93 \mu \mathrm{m}$.

$\mathrm{Sq}=0.361 \mu \mathrm{m}$;

$\mathrm{Sp}=2.02 \mu \mathrm{m}$;

$\mathrm{Sv}=1.04 \mu \mathrm{m}$;

$\mathrm{Sz}=3.06 \mu \mathrm{m}$;

$\mathrm{Sa}=0.28 \mu \mathrm{m}$;

$\mathrm{Sk}=0.848 \mu \mathrm{m}$;

$\mathrm{Spk}=0.505 \mu \mathrm{m}$;

$\mathrm{Svk}=0.341 \mu \mathrm{m}$.

Fig. 6. Near-dimple (a, c, e, g) and free-of-dimple (b, d, f, h) details (and their parameters respectively) extracted from surface after STF distinguished by: CLSM (a, b), P2ND (c, d) and P4TH (e, f); FRGR (g, h), FBDW = 0.8 mm 
When digital filtering was applied, if $\mathrm{D}_{\mathrm{DD}}<\mathrm{D}_{\mathrm{w}}$ then distortions of $A_{D D}$ increased (even the cut-off value $\mathrm{F}_{\mathrm{BDW}}>\mathrm{D}_{\mathrm{w}}$ ). When $\mathrm{D}_{\mathrm{W}}<\mathrm{D}_{\mathrm{DD}}$ and $\mathrm{D}_{\mathrm{w}}<\mathrm{F}_{\mathrm{BDW}}$ then distortion of oil pockets and near-dimple areas (as well as areas between oil pockets and/or areas between dimples and edges of studied details) did not occurred or it was negligible.

For STF distinguishing of cylindrical surfaces containing oil dimples (where $\mathrm{D}_{\mathrm{w}}>0.5 \mathrm{~mm}$ ) it is recommended of digital filtering application instead of procedure of cylinder fitting by the least squared method or polynomials (likewise $2^{\mathrm{ND}}$ degree). For minimization of dimples distortion the procedure of surface bearing area filtration or algorithm with valley digital fulfilling method can be applied as an alternative.

\section{REFERENCES}

1. Leach R. (red.): Characterisation of areal surface texture. Berlin: Springer-Verlag 2013.

2. Podulka P.: Proposal of edge-area form removal of cylindrical surfaces containing wide dimples by application of various robust processing techniques. $22^{\text {nd }}$ World Congress on the International Measurement Confederation (IMEKO), $3^{\text {rd }}-6^{\text {th }}$ September 2018, Belfast, UK (to be published)

3. Raja J., Muralikrishnan B., Fu S.: Recent advances in separation of roughness, waviness and form. Precision Engineering 26(2), 2002, pp.222-235.

4. Muralikrishnan B., Raja J.: Computational surface and roundness metrology, Springer, 2009.

5. Podulka P., Dobrzański P., Pawlus P., Lenart A.: The effect of reference plane on values of areal Surface topography parameters from cylindrical elements. Metrol. Meas. Syst. 21(2), 2014, 247-256.

6. Pawlus P., Reizer R., Wieczorowski M.: Problem of non-measured points in surface texture measurements. Metrol. Meas. Syst. 24(3), 2017, 525-536.

7. Podulka P., Pawlus P., Dobrzański P., Lenart A.: Spikes removal in surface measurement. J. Phys. Conf. Ser. 483(1), 012025 (2014).

8. Pawlus P. Wieczorowski M., Mathia T.: The errors of stylus methods in surface topography measurements. Zapol (2014).

9. Podulka P.: Problem of selection of reference plane with deep and wide valleys analysis. $22^{\text {nd }}$ World Congress on the International Measurement Confederation (IMEKO), $3^{\text {rd }}-6^{\text {th }}$ September 2018, Belfast, UK (to be published).

10. De Chiffre L., Lonardo P., Trumpold H., Lucca D.A., Goch G., Brown C.A., Raja J., Hansen H.N.: Quantitative Characterisation of Surface Texture, CIRP Annals - Manufacturing Technology, 2000, 2, 635-642, 644-652.
11. Stout K.J., Sullivan P.J., Dong W.P., Mainsah E., Luo N., Mathia T., Zahouani H.: The development of methods for the characterisation of roughness in three dimensions. Publication EUR 15178 EN Commission of the European Communities, 1993.

12. Thomas, T.R. (1999) Rough Surfaces. Second Edition, Imperial College Press, London.

13. Grabon W., Pawlus P.: Distinguishing the plateau and valley components of profiles from various types of two-process textures. Metrology and Measurement Systems 4, 2016, 593-602

14. Forbes A.B.: Least squares best fit geometric elements, NLP report DITC 40 (89), Teddington, UK, 1989.

15. Sullivan P.J.: Surface topography filtering in: Metrology and Properties of Engineering Surfaces, Springer, 2001.

16. Brinkman, S., Bodschwinna H.: Advanced Gaussian filters. In: Blunt L., Jiang X. (eds) Advanced Techniques for Assessment Surface Topography. Kogan Page Science, London and Sterling, 2003, 62-89.

17. Brinkman S., Bodschwinna H., Lemke H.-W. (2000):: Development of a robust Gaussian regression filter for three-dimensional surface analysis. $\mathrm{X}$ International Colloquium on Surfaces, Chemnitz, Germany. 122-131.

18. Kumar J., Shunmugam M. S.: Fitting of robust reference surface based on least absolute deviations. Precision Engineering 31, 2007, 102-113.

19. Lou S., Zeng W.-H., Jiang X.-Q., Scott P.J.: Robust filtration techniques in geometrical metrology and their comparison. International Journal of Automation and Computing 10/1, 2013, 1-8.

20. Podulka P.: Selection of reference plane by the least squares fitting methods. Adv. Sci. Technol. Res. J. 2016; 10(30),164-175.

21. Lou S., Jiang X., Scott P.J.: Applications of morphological operations in surface metrology and dimensional metrology. Journal of Physics: Conference Series, 2014, 483012020.

22. Janecki D.: A two-dimensional isotropic spline filter. Precision Engineering 37(4), 2014, pp.948-965.

23. Janecki D.: A generalized L-2-spline filter. Measurement 42(6), 2009, 937-943.

24. Podulka P 2018 Edge-area form removal of twoprocess surfaces with application of valley excluding method. Computational Methods in Engineering Science 2018 (CMES 2018), E3S Web of Conferences (to be published).

25. Janecki D.: Edge effect elimination in the recursive implementation of Gaussian filters. Precision Engineering 36, 2012, 128-136.

26. Godi A., Kuhle A., De Chiffre L.: A plateau-valley separation method for textured surfaces with a deterministic pattern. Precision Engineering 38, 2014, 190-196 